\title{
Increased prevalence of disciform macular degeneration after cataract extraction with implantation of an intraocular lens
} Rotterdam, The

Institute of

Ophthalmology

T L van der Schaft

C M Mooy

J H Pameyer

P T V M de Jong

Institute of Pathology

C M Mooy

W C de Bruijn

P G H Mulder

Correspondence to:

P T V M de Jong, Institute of

Ophthalmology, Erasmus

University Rotterdam,

Rotterdam, The Netherlands.

Accepted for publication

1 February 1994

Figure 1 Light microscopic image of a human macula with geographic atrophy

( $G A$, between black arrows). On the right the $(R P E)$ and the

photoreceptors $(P R)$ are atrophic. Basal laminar deposit $(B L D)$, grade 3, is present under the atrophic $R P E$. A soft druse $(D)$ can be seen between the RPE and Bruch's membrane (white arrows). The choriocapillaris (arrowheads) is located under Bruch's membrane. (Mallory stain,

magnification $\times 105$.)
Erasmus University, Netherlands

Institute of Biostatistics retinal pigment epithelium

Theo L van der Schaft, Cornelia M Mooy, Wim C de Bruijn, Paul G H Mulder, Jan H Pameyer, Paulus T V M de Jong

\begin{abstract}
After cataract extraction with implantation of an intraocular lens the increased transmission of ultraviolet and blue light may accelerate the development of age-related macular degeneration by producing free radicals in the retina. The maculae of 82 randomly selected postmortem human pseudophakic eyes and 16 fellow phakic eyes were examined by light microscopy. The presence of a basal laminar deposit, hard and soft drusen, thickening and calcification of Bruch's membrane, geographic atrophy, subretinal neovascularisation, and disciform scars was assessed in a standardised way. An age-matched series of 126 postmortem phakic eyes was used as control group. There was no difference between the two groups, except for a higher prevalence of hard drusen (exact trend test, $p=0.038$ ) and disciform scars for the pseudophakic eyes (Fisher's exact test, $p=0.007)$. There was no significant correlation between either age-related changes in the macula or disciform degeneration and the length of time between cataract surgery and death. No significant difference was found between pseudophakic eyes with or without ultraviolet filter. These findings do not confirm that disciform scar formation is caused by an increase in ultraviolet or blue light.

(Brf Ophthalmol 1994; 78: 441-445)
\end{abstract}

The most common cause of poor vision in the elderly is caractact. ${ }^{2}$ In the United States more than one million cataract operations are per-

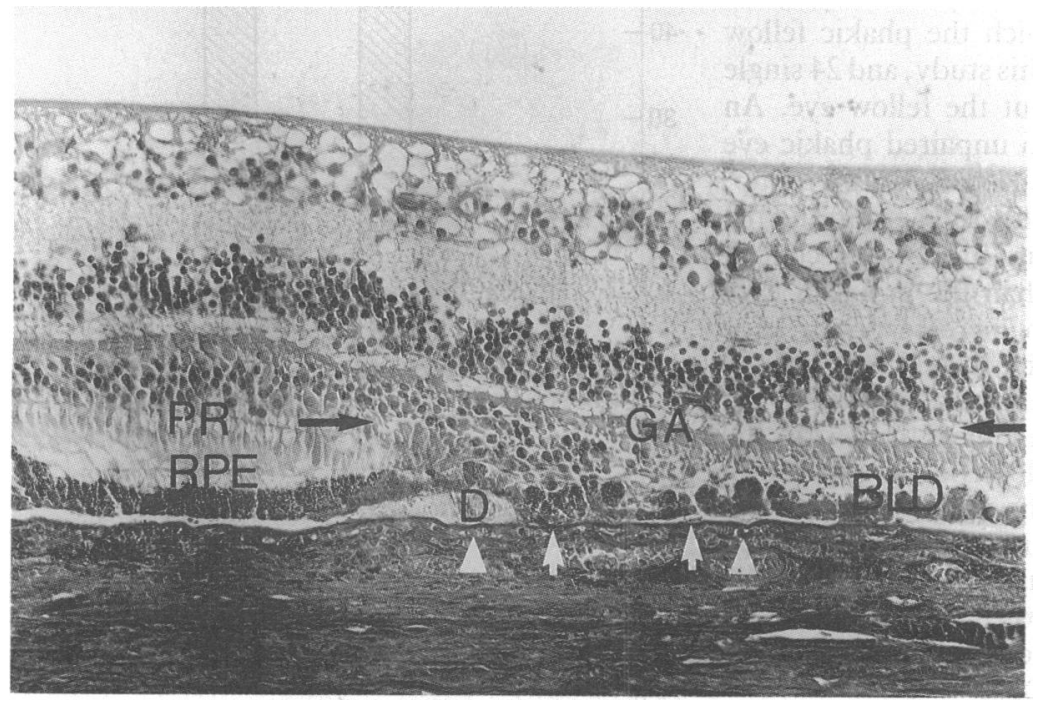

formed each year, accounting for $12 \%$ of all Medicare payments. ${ }^{34}$ After cataract extraction and implantation of an intraocular lens (IOL), visual acuity is regained in a high percentage of cases. Thus the second most common reason for visual loss in the Western world has become more important: age-related macular degeneration (ARMD), which is now the leading cause of irreversible blindness in the elderly in the Western world. ${ }^{12}$ Development of ARMD after cataract extraction and IOL implantation has been described previously. ${ }^{56}$

After the first two decades of life the natural lens becomes yellower and partly filters out the harmful blue light and ultraviolet radiation of the sun. ${ }^{78}$ With the development of cataract this filtering capacity of the lens increases, protecting the posterior pole of the eye against possible free radicals formed under the influence of the blue and ultraviolet light. ${ }^{7-11}$ At cataract extraction this biological filter is removed. During the operation, the retina is exposed to the light source of the operating microscope, which has been shown to induce phototoxic damage to the macula. ${ }^{12}$ The cataractous lens is replaced by a crystal clear IOL with or without an ultraviolet filter. It has been postulated that increased ultraviolet and blue light radiation affects normal macular functioning and thus that cataract extraction might stimulate ARMD. ${ }^{11}{ }^{13-15}$

Advanced ARMD will become manifest as either geographic atrophy of the retinal pigment epithelium (RPE) and the photoreceptors (Fig 1) or a disciform reaction, which consists of the ingrowth of new blood vessels from the choriocapillaris through Bruch's membrane under the RPE. A subsequent haemorrhage from these vulnerable vessels often results in disciform scar formation (Fig 2). ${ }^{16}$

Neovascularisation can reach the subretinal space through gaps in Bruch's membrane. ${ }^{1718}$ These gaps can be caused mechanically in the presence of extensive calcification of Bruch's membrane, ${ }^{19}$ by macrophagal enzymatic digestion $^{1820}$ or other factors. Pronounced calcification or thickening of Bruch's membrane probably increases the rigidity of this membrane and thus makes it more fragile. ${ }^{18}$

One of us ( $P$ de $J$ ) had the impression from clinical practice that extracapsular cataract extraction with implantation of an IOL in the aged was sometimes followed, within 1 month, by the development of a subretinal haemorrhage and subsequent disciform reaction. The hypothesis was formulated that ruptures in Bruch's membrane might be induced by sudden changes in intraocular pressure and in the volume of the 


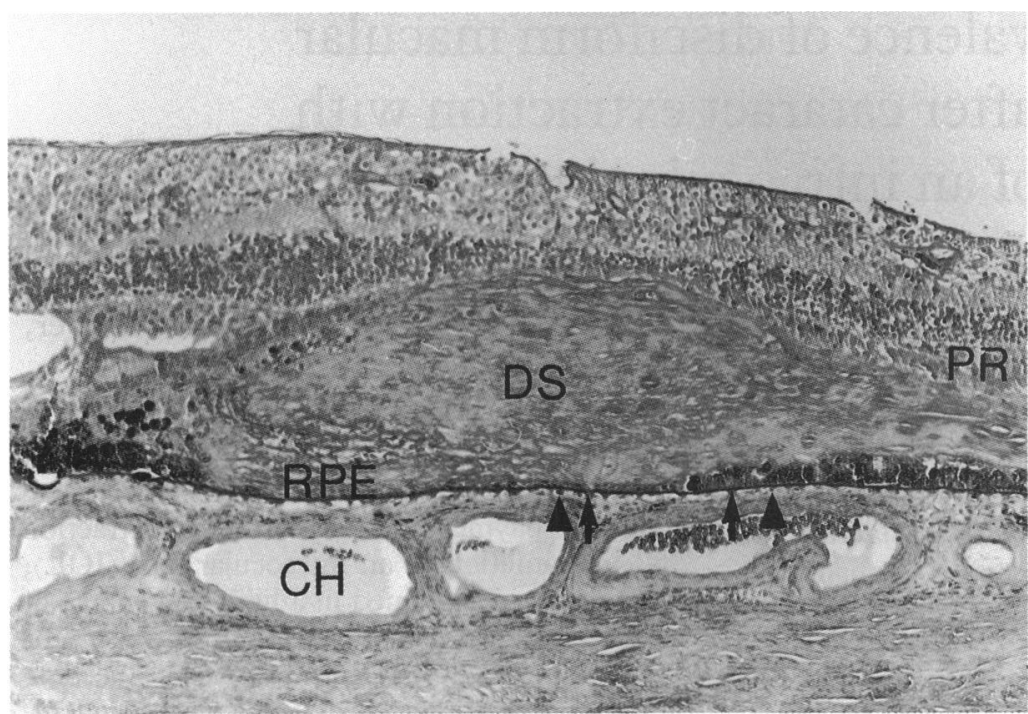

Figure 2 Light microscopic image of a human macula with a disciform scar (DS) The retinal pigment epithelium (RPE) and the photoreceptors $(P R)$ adjacent to the scar are atrophic. Bruch's membrane (small arrows),

choriocapillaris (arrowheads), $\mathrm{CH}=$ choroid. (Mallory stain, magnification $\times 65$.)

eye during surgery, which would cause deformation of the eye.

The aim of this histological investigation was to study this hypothesis and to determine the possible role of the increased transmission of blue and ultraviolet light in the development of ARMD and macular aging in pseudophakic eyes without an ultraviolet filter compared with pseudophakic eyes with an ultraviolet filter. The prevalence of ARMD in pseudophakic eyes with brown or blue irises was also compared. Literature on the histology of macular aging is extensive, ${ }^{161720-27}$ but to the best of our knowledge this is the first report on the histopathology of a series of human maculae after cataract extraction and implantation of an IOL.

\section{Materials and methods}

\section{MATERIALS}

We obtained 89 postmortem pseudophakic eyes of white humans from a corneal transplantation bank and autopsies. At a later stage seven pseudophakic eyes were excluded from this study because information on age and date of cataract extraction was not available. Otherwise no selection was made. The remaining 82 eyes included 21 pairs of pseudophakic eyes, 16 pseudophakic eyes of which the phakic fellow eye was also available for this study, and 24 single pseudophakic eyes without the fellow eye. An age-matched series of 126 unpaired phakic eye bank or autopsy eyes was used as control group. The age distributions for the study group and the control group were similar (Fig 3). The control group taken was larger than the group of eyes with an IOL in order to increase power. For statistical reasons, the subject (and not the eye) was considered to be the experimental unit.

Age at the time of death ranged from 62 to 100 years for both the pseudophakic group (mean $81 \cdot 3$ (SD 7.6) years) and the control group (mean $78.5(8.9)$ years). The difference in mean age between these two groups is not statistically significant. The time between IOL implantation and death ranged from 3 to 168 months (mean 52 (40) months, median $=48$ ).
The maculae were prepared for light microscopy as described in a previous study. ${ }^{26}$ The presence of a basal laminar deposit (BLD), hard and soft drusen, thickening and calcification of Bruch's membrane, geographic atrophy, subretinal neovascularisation, and a disciform reaction in the macula was assessed blind in a standardised way, using the classification system described earlier. ${ }^{26}$

MICROSCOPIC EXAMINATION

BLD was defined by light microscopic examination as amorphous, granular material located between the RPE and the inner layer of Bruch's membrane (Fig 1). ${ }^{2326}$ It stained pale blue with the Mallory stain. ${ }^{26}$ Thickening of Bruch's membrane was assessed with the periodic acid Schiff (PAS) stain. Calcification of Bruch's membrane was studied with the von Kossa stain, which stains calcium phosphates brownishblack. ${ }^{26}$

Drusen are deposits of material between the basement membrane of the RPE and the inner collagenous zone of Bruch's membrane. The drusen were divided into hard drusen, which were usually dome-shaped with a hyalinised appearance and stained brownish-blue with the Mallory stain, and soft drusen, which were usually larger, had sloping edges, contained granular material which stained pale blue with the Mallory stain or appeared to be optically almost empty (Fig 1).

The absence or presence of ultraviolet absorbing chromophores in the IOLs was measured with a spectrophotometer through the intact anterior segment of the eyes. As a control the anterior segments of five phakic aged eyes, one phakic eye of a 6-year-old child, two aphakic eyes, and a single IOL with and without ultraviolet filter were measured.

STATISTICAL ANALYSIS

For statistical analysis the Mann-Whitney $U$ test and the exact trend test were used to compare the presence of BLD, hard and soft drusen, and

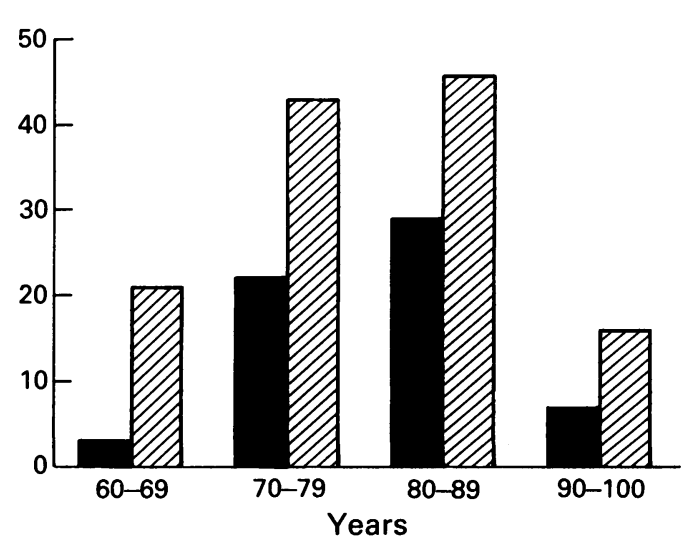

IOL eyes $\square$ Control eyes

Figure 3 Age distribution of the 61 subjects with an intraocular lens and the 126 phakic control eyes. Notice the similarity in distribution. For statistical reasons only one eye from each patient is included here. The control group was larger to increase the statistical power. 
changes in Bruch's membráne, all of which were scored from 0 to 3 in the study group and the control group. ${ }^{26}$ Fisher's exact test was used to compare the absence (class 0 ) or presence (class 1) of geographic atrophy, subretinal neovascularisation, and disciform degeneration in the pseudophakic and control eyes. For these calculations only, one randomly chosen, pseudophakic eye from each subject was used (61 eyes). The influence of the length of time between IOL implantation and death on the presence of BLD, drusen, and changes in Bruch's membrane was determined with the Spearman rank correlation test. For geographic atrophy, subretinal neovascularisation, and disciform degeneration the Mann-Whitney U test was used. For comparison of differences in changes due to macular degeneration between pseudophakic eyes with and without ultraviolet filter, between eyes with brown and blue irises, and between eyes that underwent an intra- or extracapsular cataract extraction, the Mann-Whitney U test was used for BLD, drusen, and changes in Bruch's membrane. Fisher's exact test was used for geographic atrophy, subretinal neovascularisation, and disciform degeneration. For the latter associations within the IOL study group, all 82 pesudophakic eyes were used. p Values below 0.05 were considered statistically significant. Two sided $\mathrm{p}$ values were used throughout. For comparison of the histological classification of fellow phakic eyes Wilcoxon's matched pairs signed rank test was used.

\section{Results}

The prevalences of BLD, drusen, and thickening and calcification of Bruch's membrane for both the study group and the control group are given in Table 1. No significant differences were found between the IOL group and the control group except for a significantly higher prevalence of hard drusen in the IOL group (exact trend test and Mann-Whitney $U$ test, $p=0.038$ ). The distribution of the classification scores (ranging from 0 to 3 ) determined for the histological changes did not differ significantly between the study group and the control group.

In Table 2 the prevalences of geographic atrophy, subretinal neovascularisation, and disciform degeneration are given. A significantly higher percentage exhibited disciform degeneration in the IOL group than in the control group (Fisher's exact test, $\mathrm{p}=\mathbf{0} \cdot 007$ ). No significant differences were found in geographic atrophy and subretinal neovascularisation between the two groups.

In three maculae the disciform scar was flat and in one case the overlying RPE was only

Table 1 The prevalence of histological age-related changes in the maculae of 61 unpaired eyes with an intraocular lens (IOL) and 126 phakic eyes of the age-matched control group

\begin{tabular}{|c|c|c|c|c|c|}
\hline & \multicolumn{2}{|l|}{ Drusen ${ }^{\star}$} & \multirow{2}{*}{$\begin{array}{l}\text { Basal } \\
\text { laminar } \\
\text { deposit }\end{array}$} & \multicolumn{2}{|c|}{ Bruch's membrane ${ }^{\star}$} \\
\hline & Hard & Soft & & Thickening & Calcification \\
\hline $\begin{array}{l}\text { IOL group (\%) } \\
\text { Control group (\%) }\end{array}$ & $\begin{array}{l}38(62) \dagger \\
57(45) \dagger\end{array}$ & $\begin{array}{r}9(15) \\
18(14)\end{array}$ & $\begin{array}{l}40(66) \\
69(55)\end{array}$ & $\begin{array}{r}55(90) \\
122(97)\end{array}$ & $\begin{array}{l}49(80) \\
96(76)\end{array}$ \\
\hline
\end{tabular}

ॠThe scoring scale with a range of 0 to 3 was dichotomised into 0 (absent) and larger than 0 (present). †Mann-Whitney $U$ test and exact trend test, $p=0.038$. partially atrophic. The other two maculae had a thick scar which clearly elevated the retina (Fig 2). The overlying RPE was again partially atrophic in only one macula.

In three of the five maculae with a disciform scar Bruch's membrane was locally abnormally thin, alternating with the normally thickened membrane for that age.

The time between IOL implantation and death of four subjects with disciform macular degeneration was $6,42,60$, and 126 months (mean 58 months). For one eye this information was not available. However, the exact time between IOL implantation and the development of a disciform scar could not be retrieved. The mean age of the patients with a disciform reaction at the time of enucleation was 83 years.

The differences between the IOL and the control group for geographic atrophy and subretinal neovascularisation were not statistically significant. None of these changes exhibited a significant correlation with the length of time between implantation of the IOL and death.

The signed ranks test revealed no significant difference in age-related changes or degeneration of the macula between the eyes of pairs consisting of one pseudophakic and one phakic eye.

No significant differences in histological macular changes could be found between eyes for pairs of pseudophakic eyes, even when the eyes with an IOL implant for the longest period of time were compared with the fellow eye with an implant of shorter duration (mean time difference 28 months, range 6 to 78 months).

No significant differences in histological macular changes were found between the 16 pairs of pseudophakic and their fellow phakic eyes.

In $43 \%$ of pseudophakic eyes the IOL had an ultraviolet filter, whereas $41 \%$ of eyes received an IOL without an ultraviolet filter. The anterior segment of the remaining $16 \%$ was not available for measurement of ultraviolet light transmittance. Ultraviolet filtering chromophores blocked nearly all light with a wavelength shorter than $400 \mathrm{~nm}$, thus including the absorption of ultraviolet $B(290-320 \mathrm{~nm})$, ultraviolet $A_{1}(320$ $340 \mathrm{~nm})$, and ultraviolet $\mathrm{A}_{2}(340-400 \mathrm{~nm})$, but letting violet and blue light $(400-500 \mathrm{~nm})$ through. The cornea absorbed all light with a wavelength shorter than $310 \mathrm{~nm}$. The biological lens of the 6-year-old child had a sharp absorption threshold at $390 \mathrm{~nm}$ in contrast with aged lenses, which had a sloping absorption curve, starting at $600 \mathrm{~nm}$ and decreasing to a nearly total block at $500 \mathrm{~nm}$.

No significant differences in macular aging or degenerative changes were found between pseudophakic eyes with or without an ultraviolet

Table 2 Prevalence of histological macular degeneration in 61 unpaired eyes with an intraocular lens (IOL) and 126 phakic eyes of the age-matched control group

\begin{tabular}{llll}
\hline & $\begin{array}{l}\text { Geographic } \\
\text { atrophy }\end{array}$ & $\begin{array}{l}\text { Subretinal } \\
\text { neovascularisation }\end{array}$ & $\begin{array}{l}\text { Disciform } \\
\text { scar }\end{array}$ \\
\hline IOL group (\%) & $4(7)$ & $5(8)$ & $5(8)^{\star}$ \\
Control group (\%) & $7(6)$ & $4(3)$ & $0(0)^{\star}$ \\
\hline
\end{tabular}

^Fishers's exact test, $\mathrm{p}=0.007$. 
filter, nor between pseudophakic eyes after intraor extracapsular cataract extraction. Of the five eyes with a disciform scar, three IOLs had an ultraviolet filter. In four of the five pseudophakic eyes with a disciform scar the IOLs were implanted after extracapsular cataract extraction. No statistically significant differences were found between pseudophakic eyes with brown or blue irises.

\section{Discussion}

In this study we found a significantly higher prevalence of histological disciform macular degeneration after cataract extraction and subsequent implantation of an IOL than for an agematched control group of phakic eyes. This is further reinforced by the observation of subsequent disciform macular degeneration in one of the seven pseudophakic eyes that were excluded from the series because of a lack of information about age. It is assumed that the longer a lens is in situ, the longer free radicals can be formed in the eye by photic energy, a process which can damage the retina. ${ }^{13}$ However, there was no significant correlation between the period of time between IOL implantation and death and the histological degree of aging or degeneration of the macula. The absence of ultraviolet blocking chromophores in the IOLs was not associated with an increase in macular aging or degeneration. There was no significant correlation between iris colour and macular aging. Therefore our findings do not support the assumed increase in both the formation of free radicals and macular aging or degeneration.

The results of several studies on the prevalence of cataract and ARMD are rather contradictory. Some authors think that the development of a cataract protects the eye from harmful ultraviolet light which might stimulate the development of ARMD. ${ }^{511}$ Others conclude that cataract and ARMD are age-related changes which develop simultaneously in the same person. ${ }^{16}$ The results of another study indicate a direct correlation between ARMD and cortical cataract and an inverse correlation between ARMD and nuclear cataract.' Aphakic eyes exhibited a twofold increase in the prevalence of ARMD with respect to phakic eyes without lens opacities.?

Our own results suggest that the incidence of disciform macular degeneration is higher after cataract extraction with an IOL implant than would be expected for a normal population. However, we must keep in mind that a few cell layers of fibrocytes, considered to be the beginning of a disciform scar, can only be seen by the pathologist and not by the ophthalmologist with biomicroscopy. Clinically a disciform scar is first visible when it comprises five or six cell layers. ${ }^{17}$ Therefore clinical data on disciform macular degeneration might represent an underestimation compared with our histological data. In the Food and Drug Administration (FDA) report on intraocular lenses, postoperative macular degeneration was not considered as an adverse reaction but as a confounder and these eyes (number not mentioned) were excluded from the results. ${ }^{28}$
For the development of disciform macular degeneration there must be an ingrowth of new vessels, originating from the choriocapillaris, into the sub-RPE space. Normally Bruch's membrane forms a firm continuous mechanical barrier between the choriocapillaris and the RPE. Thus a pathway through Bruch's membrane must be created.

One possibility is that the surgical trauma causes ruptures in Bruch's membrane, which is known to be more fragile when thickened and calcified. ${ }^{16}$ The subsequent passage of new vessels from the choroid into the sub-RPE space is followed by exudation of serous fluid or haemorrhage and the formation of a disciform scar. In the four eyes with a disciform scar, Bruch's membrane was not more calcified than in either the other pseudophakic or the control eyes. In the fifth eye Bruch's membrane was markedly calcified, like an eggshell, and exhibited many breaks. If we assume that calcification is the main indicator for fragility of Bruch's membrane, our findings do not confirm the hypothesis that breaks in a calcified Bruch's membrane are the main cause of postoperative subretinal neovascularisation, but it can be one of the causes.

A second explanation might be that macrophages, coming from the choroid, create a pathway for neovascularisation by breaking down the layers of Bruch's membrane. Usually the thickness of Bruch's membrane increases with age, ${ }^{26}$ but in our study Bruch's membrane in three maculae with a disciform scar was abnormally thin and sometimes even showed breaks, which were covered by the scar tissue. Adjacent to these breaks, at the side of the choriocapillaris, histiocytic cells were seen in two of these eyes. Others reported that after experimental laser coagulation of the retina, Bruch's membrane first remained intact. ${ }^{29}$ However, macrophages were attracted, probably by released chemotactic factors, and created gaps in Bruch's membrane after several days or weeks. ${ }^{29}$ Macrophages can also induce angiogenesis. ${ }^{30}$ This laser induced chemoattraction of macrophages might be similar to the mechanism in eyes with an IOL, in which cataract extraction or more generally the surgical trauma acted as the initiating factor for release of chemotactic factors that attract macrophages.

A third explanation is based on the differences, seen in Table 2 , in subretinal neovascularisation between the control group of normal phakic eyes (3\%) and the IOL group (8\%). It is well known that these new vessels easily leak or bleed, even under physiological conditions. ${ }^{17}$ During surgery several non-physiological conditions occur, such as the rise in orbital pressure during peribulbar anaesthesia, the drop in intraocular pressure after incision, and mechanical forces arising from manipulation of the eye, irrigation, and aspiration of lens material, and nowadays the highly energetic ultrasound waves used for phacoemulsification. All of these non-physiological conditions might weaken preexisting new vessels or provoke further outgrowth or haemorrhage and thus subsequent disciform reaction.

Other possibilities are the infiltration of 
Bruch's membrane by endothelial cells and pericytes of the choriocapillaris without pre-existing breaks. ${ }^{20}$ Even the infiltration of Bruch's membrane by single RPE cells has been reported. ${ }^{31}$ The importance of the latter two possibilities is unknown.

The prevalence of large confluent soft drusen, clinically often associated with neovascularisation, in the IOL group was similar to that in the control group so it is unlikely that soft drusen are responsible for the difference in the prevalence of disciform reactions. ${ }^{22} 24$

The higher prevalence of hard drusen in pseudophakic eyes compared with phakic eyes could not be explained. However, the presence of hard drusen is not correlated with serious loss of vision' or with the development of a disciform reaction, ${ }^{2122}$ and a causal relation is thus unlikely.

There was no significant relation between the presence of cataract and the development of agerelated changes in the macula. Thus there was no indication that protection of the retina against ultraviolet light by the cataractous lens in the years before cataract extraction had prevented aging or other degenerative changes in the macula.

The best reference for assessment of the changes in a pseudophakic eye after age-related cataract surgery is the non-operated phakic fellow eye, because the only difference between the fellow eye and the pseudophakic eye is the cataract extraction with implantation of an IOL and the resulting change in conditions. No differences were found between these two groups of eyes. However, the number of pairs was relatively small so that no valid conclusions can be drawn from this finding.

We can conclude that in this study increased prevalences of histological disciform macular degeneration and hard drusen were found after cataract extraction with implantation of an IOL. The exact cause remains unclear, but a direct relation between either an increase in ultraviolet light on the retina caused by IOLs without ultraviolet filter or the duration of the increased amount of ultraviolet light could not be demonstrated. As far as the disciform scars are concerned it seems more likely that either the harmful effects of surgical trauma on Bruch's membrane or pre-existing sub-RPE vessels or the attraction of macrophages, which break down Bruch's membrane and stimulate neovascular membrane formation, plays an important role. Further research is necessary to discover any predictable risk factors or causes that can be avoided.

Presented in part at the annual meeting of the Association for Research in Vision and Ophthalmology (ARVO), Sarasota, Florida, USA, 7 May 1992 and at the 18th meeting of the Club Jules Gonin, Vienna, Austria, 8 September 1992.

The authors certify that they have no affiliation with or financial The authors certify that they have no affiliation with or financial
involvement in any organisation or entity with a direct financial involvement in any organisation or entity with a direct financial
interest in the subject matter or materials discussed in the manuscript.
We thank Eurotransplant Foundation, Leiden, the cornea bank of the Netherlands Ophthalmic Research Institute, Amsterdam, and the Eye Hospital Rotterdam for providing most of the eyes.

1 Leibowitz HM, Krueger DE, Maunder LR, Milton RC, Kini $M M$, Kahn HA, et al. Framingham eye study monograph. MM, Kahn HA, et al. Framingham eye study

2 Klein BE, Klein R. Cataracts and macular degeneration in older Americans. Arch Ophthalmol 1982; 100: 571-3.

3 Jensen AD. Cataract PPOs. Arch Ophthalmol 1990; 108: 501-2.

4 Foreman J. Federal agency to develop cataract management guidelines by January 1991. Arch Ophthalmol 1990; 108: 1391 .

5 Van de Hoeve J. Senile Makuladegeneration und senile Linsentrübung. Graefes Arch Ophthalmol 1918; 98: 1-6.

6 Gjessing HGA. Gibt es einen Antagonismus zwischen Cataracta senilis und Haabscher seniler Makula Veränderungen? Acta Ophthalmol 1953; 31: 401-21.

7 Liu IY, White L, La Croix AZ. The association of age-related macular degeneration and lens opacities in the aged. macular degeneration and lens op

8 Lerman S. Ocular photoxicity. $N E$ Engl $\mathcal{F}$ Med 1988; 319: 1475-7.

9 Rao NA, Thaete LG, Delmage JM, Sevanian A. Superoxide dismutase in ocular structures. Invest Ophthalmol Vis Sci 1985; 26: 1778-81.

10 Mainster MA, Han WT, Delori FC. Potential retinal hazards. Ophthalmology 1983; 90: 927-32.

11 Young RW. Solar radiation and age-related macular degeneration. Surv Ophthalmol 1988; 32: 252-69.

12 Michels M, Sternberg P. Operating microscope-induced retinal phototoxicity: pathophysiology, clinical manifestaretinal phototoxicity: pathophysiology, clinical manifest

13 Taylor HR, Munoz B, West S, Bressler NM, Bressler SB, Rosenthal FS. Visible light and risk of age-related macular degeneration. Trans Am Ophthalmol Soc 1990; 88: 163-73.

14 Zrenner E. Lichtindizierte Schade am Augen. Fortschr Ophthalmol 1990; 87: 941-51.

15 Werner JS, Steele VG, Pfoff DS. Loss of human photoreceptor sensitivity associated with chronic exposure to ultraviolet radiation. Ophthalmology 1989; 96: 1552-8.

16 Green WR. Pathology of the macula. In: Spencer WH, ed. Ophthalmic pathology. 3rd ed. Philadelphia: Saunders, 1985; 2: 924-89, 1023 .

17 Sarks SH. New vessel formation beneath the retinal pigment epithelium in senile eyes. Brf Ophthalmol 1973; 57:951.

18 Penfold PL, Killingsworth MC, Sarks SH. An ultrastructural study of the role of leucocytes and fibroblasts in the breakdown of Bruch's membrane. Aust f Ophthalmol 1984 12: $23-31$

19 Garner A. Pathology of macular degeneration in the elderly. Trans Ophthalmol Soc UK 1975; 95: 54-61.

20 Killingsworth MC, Sarks JP, Sarks SH. Macrophages related to Bruch's membrane in age-related macular degeneration. Eye 1990; 4: 613-21.

21 Sarks SH. Ageing and degeneration in the macular region: a clinico-pathological study. $B r \mathcal{F}$ Ophthalmol 1976; 60: 324 41.

22 Green RW, McDonnel PJ, Yeo JH. Pathologic features of senile macular degeneration. Ophthalmology 1985; 92: 61527.

23 Schaft TL van der, de Bruijn WC, Mooy CM, Ketelaars GAM, De Jong PTVM. Is basal laminar deposit unique for agerelated macular degeneration? Arch Ophthalmol 1991; 109 . 420-5.

24 Sarks JP, Sarks SH, Killingsworth MC. Evolution of geographic atrophy of the retinal pigment epithelium. Eye 1988; 2: 552-77.

25 Young RW. Pathophysiology of age-related macular degeneration. Surv Ophthalmol 1987; 31: 291-305.

26 Schaft TL van der, Mooy CM, de Bruijn WC, Oron FG, Mulder PGH, de Jong PTVM. Histologic features of the early stages of age-related macular degeneration: a statistical early stages of age-related macular degener
analysis. Ophthalmology 1992; 99: 278-86.

27 Schaft TL van der, de Bruijn WC, Mooy CM, Ketelaars GAM, de Jong PTVM. Element analysis of the early stages of agerelated macular degeneration. Arch Ophthalmol 1992; 110: 389_94.

28 Stark WJ, Worthen DM, Holladay JT, Bath PE, Jacobs ME, Murray GC, et al. The FDA report on intraocular lenses. Ophthalmology 1983; 90: 311-7.

29 Pollack A, Korte GE, Weitzner AL, Henkind P. Ultrastructure of Bruch's membrane after krypton laser photocoagulation. I Breakdown of Bruch's membrane. Arch Ophthalmol 1986; 104: 1372-6.

30 Penfold PL, Provis JM, Billson FA. Age-related macular degeneration: ultrastructural studies of the relationships of leucocytes to angiogenesis. Graefes Arch Clin Exp leucocytes to angiogenesis.
Ophthalmol 1987; 225:70-6.

31 Grindle CFJ, Marshall J. Ageing changes in Bruch's membrane and their functional implications. Trans Ophthalmol Soc UK 1978; 98: 172-5. 